\title{
Maternal periodontitis and its influence on duration of gestation and fetal birth weight
}

\author{
Swetha Munivenkatappa ${ }^{1}$, Srinivas M. Govindaraj ${ }^{2 *}$
}

\begin{abstract}
${ }^{1}$ Department of Obstetrics and Gynecology, Narayana Medical College, Nellore, Andhra Pradesh, India ${ }^{2}$ Department of Medical Gastroenterology, Narayana Medical College, Chintareddypalem, Nellore, Andhra Pradesh, India
\end{abstract}

Received: 20 June 2019

Revised: 29 June 2019

Accepted: 09 July 2019

\section{*Correspondence:}

Dr. Srinivas M. Govindaraj,

E-mail: drmgsri@yahoo.co.in

Copyright: ( ) the author(s), publisher and licensee Medip Academy. This is an open-access article distributed under the terms of the Creative Commons Attribution Non-Commercial License, which permits unrestricted non-commercial use, distribution, and reproduction in any medium, provided the original work is properly cited.

\section{ABSTRACT}

Background: There has been a lot of interest in knowing the effects of oral health on adverse pregnancy outcomes like preterm births and low birth weight. Studies have yielded contradicting results and there are lot of confounding issues that blur the picture. Aim of the study is to determine the prevalence of periodontitis is pregnant population and determine the effect of periodontitis on preterm births and low birth weight.

Methods: This was a cross sectional study of singleton pregnant women attending ante-natal checkups with oral interview and clinical examination. Oral examination was done at the beginning of third trimester of pregnancy. They were followed up to delivery to note the duration of gestation, birth weight of babies.

Results: The prevalence of periodontitis was $22 \%$ with $90.9 \%$ having mild and $9.1 \%$ having moderate periodontitis. Maternal education (high school and above) was associated with lower prevalence of periodontitis $(\mathrm{p}=0.042)$. There was no difference in the birth weights between the group with and without periodontitis $(2.9 \pm 0.41 \mathrm{kgs}$ vs $2.74 \pm 0.36 \mathrm{kgs}, \mathrm{p}=0.11)$. The incidence of low birth weights was also similar $(\mathrm{p}=0.22)$. The average gestational age was slightly less in the group with periodontitis (38 weeks 3 days vs 37 weeks 5 days) but the rates of preterm births were similar between the two groups $(\mathrm{p}=0.61)$.

Conclusions: Mild/moderate periodontitis does not appear to have a significant effect on pre-term births and low birth weight. Maternal education and awareness seem to mitigate development of periodontitis and adverse pregnancy outcomes.

Keywords: Ante-natal care, Duration of gestation, Low birth weight, Maternal education, Periodontitis, Preterm birth

\section{INTRODUCTION}

Maternal health including oral health has important implications on the outcome of pregnancy. Comprehensive prenatal health care should include oral health evaluation but is often neglected. It is estimated that $50 \%$ of pregnant women suffer from periodontitis. ${ }^{1}$ Hormonal changes in pregnancy alters the inflammatory milieu and predispose to periodontal inflammation.
Persistent periodontal infection leads to chronic systemic inflammation that can adversely affect pregnancy Outcome-causing preterm birth, preeclampsia, gestational diabetes, small for gestation babies and fetal loss. ${ }^{2-4}$ Three fourth of perinatal mortality is due to preterm births. Nearly $18 \%$ of preterm low birth weight deliveries are attributable to periodontitis. Inflammatory cytokines like IL1, IL6 and TNF alpha increase prostaglandin synthesis and precipitate labour. ${ }^{5}$ Periodontitis is a risk 
factor for low birth weight and pre-term births in India. ${ }^{6,7}$ Periodontitis, especially severe, is associated with $200 \%$ increased risk of preeclampsia. However not all studies support these findings. ${ }^{8,9}$ Benefits of treating periodontitis in pregnancy have also yielded diverse results. ${ }^{10}$ Adverse pregnancy outcomes are multifactorial and there is significant overlap of factors which can also contribute to the development of periodontitis. This study intends to look at the prevalence of periodontitis and demographic features associated with periodontitis among rural pregnant woman attending pre-natal health checkups and possible effect of periodontitis on preterm births and birth weight.

\section{METHODS}

\section{Study population}

The subjects were enrolled by convenience sampling from the areas adopted by our medical college as a part of community out-reach program. 100 pregnant woman entering into their third trimester and attending to routine ante-natal checkup were enrolled. Women in the age group of 18-35 years, having a singleton pregnancy and having at least 20 teeth were included. The exclusion criteria were multiple pregnancies; HIV seropositivity; mothers with a systemic disease such as cardiovascular disease, hepatic insufficiency, glomerulonephritis, hyperthyroidism, or epilepsy; placental or uterine abnormalities; and mothers who received systemic antibiotics during pregnancy and had undergone periodontal therapy during pregnancy.

\section{Data collection}

The data from the expectant mothers were collected by interview and clinical examination and recorded using a standard questionnaire. The questionnaire included information regarding personal details, household information, demographic data, behavioral habits, medical history, and obstetric history. Personal details included were age, place of residence, and religion/caste. In the household information, details regarding duration of married life, consanguinity, type of housing, sanitation, water supply, and Socio Economic Status were recorded. Demographic data included were maternal schooling, maternal employment status, and family income over the last month (calculated by summing the incomes of all the members of the household). Other details that were recorded are dietary habits, brushing aids, duration of brushing, alcohol consumption, and illegal drugs and tobacco use during pregnancy. In obstetric history, the following details were recorded - the number of ante-natal consultations (ANC), last menses period. The following variables were recorded: height, weight, body mass index $\left(\mathrm{kg} / \mathrm{m}^{2}\right)$, blood pressure, hemoglobin, and blood group. Socio-economic strata was classified based on Modified BG Prasad scale, updated for January 2017. At delivery maternal general health during pregnancy, and any morbidity during pregnancy like hypertension, anemia, diabetes, infections during pregnancy, pre-eclampsia, placental abruption, intrauterine growth retardation, vaginal bleeding, $\mathrm{Rh}$ factor isoimmunity, and their treatment was collected in addition to gestational age of baby, birth weight. Main pregnancy outcomes were gestational age and birth weight. Delivery before 37 weeks of gestation was defined as pre-term birth and birth weight less than $2500 \mathrm{gms}$ was taken as low birth weight.

\section{Periodontal examination}

An intra-oral examination was carried out by a single periodontologist and following parameters were recorded - bleeding on probing (BOP), measurement of probing depth (PD), and clinical attachment level (CAL). PD was measured from the free gingival margin to the bottom of the gingival sulcus/periodontal pocket using a periodontal probe. CAL was measured from the cement enamel junction to the base of the gingival sulcus/pocket. Distance was rounded down to the nearest whole millimeter. Two randomly chosen quadrants-one in upper and one in lower jaw were examined. Periodontitis was diagnosed according to the modified Gomes-Filho criteria. ${ }^{11}$ (Table 1) BOP was recorded as positive if it occurs within 15 seconds of probing.

Table 1: Diagnostic criteria for periodontitis - GomesFilho, et al modified.

\begin{tabular}{|lll|}
\hline $\begin{array}{l}\text { Severity } \\
\text { evel }\end{array}$ & $\begin{array}{l}\text { Probing depth } \\
\text { (PD) }\end{array}$ & $\begin{array}{l}\text { Clinical } \\
\text { attachment } \\
\text { level }\end{array}$ \\
\hline $\begin{array}{l}\text { Severe } \\
\text { periodontitis }\end{array}$ & $\begin{array}{l}\geq 2 \text { teeth with } \geq 1 \\
\text { site with } \mathrm{PD} \geq 5 \\
\mathrm{~mm}\end{array}$ & $\begin{array}{l}\geq 5 \mathrm{~mm} \text { on the } \\
\text { same site }\end{array}$ \\
\hline $\begin{array}{l}\text { Moderate } \\
\text { periodontitis }\end{array}$ & $\begin{array}{l}\geq 2 \text { teeth with } \geq 1 \\
\text { site with } \mathrm{PD} \geq 4 \\
\mathrm{~mm}\end{array}$ & $\begin{array}{l}\geq 3 \mathrm{~mm} \text { on the } \\
\text { same site }\end{array}$ \\
\hline $\begin{array}{l}\text { Mild } \\
\text { periodontitis }\end{array}$ & $\begin{array}{l}\geq 2 \text { teeth with } \geq 1 \\
\text { site with } \mathrm{PD} \geq 4\end{array}$ & $\begin{array}{l}\geq 1 \text { mm on the } \\
\text { sme site }\end{array}$ \\
\hline $\begin{array}{l}\text { No } \\
\text { periodontitis }\end{array}$ & Not satisfying the above criteria \\
\hline
\end{tabular}

\section{Statistical analysis}

The statistical analysis was performed using SPSS ver. 21.0 (SPSS Inc., Chicago, IL, USA). The distribution of maternal socio-demographic characteristics, medical history and clinical findings according to the presence and absence of periodontitis were compared. Continuous variables were expressed as mean with standard deviation. Categorical variables were expressed as ratios. ANOVA test was used to compare means of continuous variables. Chi square test or Fisher exact test was used to compare categorical variables. Statistical significance was considered at a $5 \%$ level. 


\section{RESULTS}

A total of 100 pregnant women were included in the study. None of the participants had been exposed to oral health education or periodontal therapy before the study.

The prevalence of periodontitis was $22 \%$ in the study population. $20(90.9 \%)$ had mild periodontitis and 2 $(9.1 \%)$ had moderate periodontitis. None had severe periodontitis. 21 women had only bleeding on probing without an increase in probe depth or clinical attachment loss and were considered not to have periodontitis. The average probe depth was $3.28 \mathrm{~mm}(\mathrm{SD} \pm 0.6)$ and was higher in those with periodontitis $(4.27 \pm 0.63 \mathrm{~mm}$ vs $2.87 \pm 0.34 \mathrm{~mm})$.

The mean clinical attachment level was $0.9 \mathrm{~mm}$ $(\mathrm{SD} \pm 0.85)$. It was $1.68 \mathrm{~mm}(\mathrm{SD} \pm 0.84)$ in those with periodontitis and $0.68 \mathrm{~mm}(\mathrm{SD} \pm 0.71)$ in those without periodontitis.

The mean age of the participants was 22.85 years $(\mathrm{SD} \pm 3.43)$. Periodontitis prevalence increased with age with $50 \%$ prevalence in $31-35 y$ group. All the women reported brushing teeth daily with a toothbrush. The average time spent on oral hygiene related activities was $11 \pm 12.9 \mathrm{~min}$ per day $(13 \pm 16.2 \mathrm{~min}$ vs $10.4 \pm 11.9 \mathrm{~min}$ in those with and without periodontitis respectively, $\mathrm{P}=0.39$ ). Both the groups had similar ante-natal care visits $(6.9 \pm 2.9$ vs $6.7 \pm 2.6$ visits in those with and without periodontitis respectively, $\mathrm{p}=0.94)$. Also there was no difference between the groups with and without periodontitis with respect to weight $(56.6 \pm 9.5 \mathrm{~kg}$ vs $58.6 \pm 10 \mathrm{~kg}, \mathrm{p}=0.41)$, systolic BP $(108 \pm 11.4 \mathrm{mmHg}$ vs $108 \pm 11.4 \mathrm{mmHg}, \mathrm{p}=0.97)$ or diastolic BP $(70 \pm 10 \mathrm{mmHg}$ vs $68.3 \pm 10.5 \mathrm{mmHg}, \mathrm{p}=0.63)$, mean blood sugars $(87 \pm 16.7 \mathrm{mg} \%$ vs $86.5 \pm 11.7 \mathrm{mg} \%, \quad \mathrm{p}=0.87)$ and hemoglobin levels $(10.6 \pm 1.5 \mathrm{gm} \%$ and $10.7 \pm 1.6 \mathrm{gm} \%$ $(\mathrm{p}=0.75)$. (Table 2) 11, 29, 42, 16 and 2 were in low, lower middle, middle, upper middle and upper income group respectively with no difference in the prevalence of periodontitis between different socio-economic strata $(p=0.53)$. There was no difference between the group with and without periodontitis with respect to the type of housing $(\mathrm{p}=0.5)$, socio-economic strata $(\mathrm{p}=0.53)$, source of water for consumption $(\mathrm{p}=0.35)$, maternal blood group $(\mathrm{p}=0.86)$. Hypothyroidism was the most common associated co-morbidity found in $11 \%$ of pregnant woman. All were taking adequate thyroid hormone supplements. Hypothyroidism was not associated with development of periodontitis $(\mathrm{p}=0.86)$. None reported using alcohol or tobacco. Only 5 had not received any formal schooling. 6, 12, 37, 40 had attended primary, mid-level, high school and college education respectively. Maternal education level seems to influence the prevalence of periodontitis. (Figure 1) Woman with less formal education tended to have more periodontitis $(p=0.004)$. Also type of maternal employment was associated with the development of periodontitis $(\mathrm{p}=0.006)$.

Table 2: Characteristics of study participants.

\begin{tabular}{|lllll|}
\hline & All & With periodontitis & No periodontitis & p value \\
\hline Age (years) & $22.85( \pm 3.4)$ & $23.32( \pm 4.1)$ & $22.72( \pm 3.2)$ & 0.47 \\
\hline ANCs & $6.7( \pm 2.7)$ & $6.9( \pm 2.9)$ & $6.7( \pm 2.6)$ & 0.94 \\
\hline Weight $(\mathrm{kgs})$ & $58.2( \pm 9.9)$ & $56.6( \pm 9.5)$ & $58.6( \pm 10)$ & 0.41 \\
\hline Time for oral hygine (mins) & $11( \pm 12.9)$ & $13( \pm 16.2)$ & $10.4( \pm 11.9)$ & 0.39 \\
\hline Systolic BP (mmHg) & $108( \pm 11.3)$ & $108( \pm 11.4)$ & $108( \pm 11.40)$ & 0.97 \\
\hline Diastolic BP (mmHg) & $68.6(10.3)$ & $70( \pm 10)$ & $68.3( \pm 10.5)$ & 0.63 \\
\hline $\mathrm{Hb}(\mathrm{g} \%)$ & $10.7( \pm 1.6)$ & $10.6( \pm 1.5)$ & $10.7( \pm 1.6)$ & 0.75 \\
\hline RBS (mg\%) & $86.6( \pm 12.9)$ & $87( \pm 16.7)$ & $86.5( \pm 11.7)$ & 0.87 \\
\hline Hb (at delivery) & $9.8( \pm 1.4)$ & $9.9( \pm 1.3)$ & $9.7( \pm 1.4)$ & 0.44 \\
\hline Hypothyroid & 11 & 3 & 8 & 0.70 \\
\hline Family income $($ Rs/yr) & $11270( \pm 6733)$ & $11864( \pm 9843)$ & $11103( \pm 5633)$ & 0.64 \\
\hline Probe depth (mm) & $3.28( \pm 0.6)$ & $4.27( \pm 0.63)$ & $2.87( \pm 0.34)$ & 0.00 \\
\hline Clinical Attachment Level $(\mathrm{mm})$ & $0.9( \pm 0.85)$ & $1.68( \pm 0.84)$ & $0.68( \pm 0.71)$ & 0.00 \\
\hline Maternal schooling* & & $9 / 13$ & $14 / 64$ & 0.042 \\
\hline$*$ (Less than/More than High School) & & & & \\
\hline
\end{tabular}

\section{Periodontitis and birth weight/pre-term birth}

The mean duration of pregnancy was 38 weeks 2 days ( $\mathrm{SD} \pm 9$ days). The duration of gestation was 35 weeks 4 days ( $\mathrm{SD} \pm 4$ days) in the pre-term group and 38 weeks 5 days ( $\mathrm{SD} \pm 5$ days) in the term group. The average duration of pregnancy was 38 weeks 3 days $(\mathrm{SD} \pm 9$ days, 95\% CI=38weeks 1 day - 38weeks 5 days) and 37 weeks 5 days $(\mathrm{SD} \pm 8.6$ days, $95 \% \mathrm{CI}=37$ weeks 1 day -38 weeks 2 days) in the group without and with periodontitis 
respectively $(p=0.024)$. Figure 2 shows the median and quartile distributions of duration of gestation according to periodontal status. Pre-term deliveries were $14 \%$ of the total deliveries with 11 in the group with-out periodontitis and 3 in the group with periodontitis $(p=0.61)$ (Figure 3 ). The odds ratio for pre-term delivery in periodontitis group was 0.96 (95\% CI 0.24-3.8, p=0.95) (Table 3).

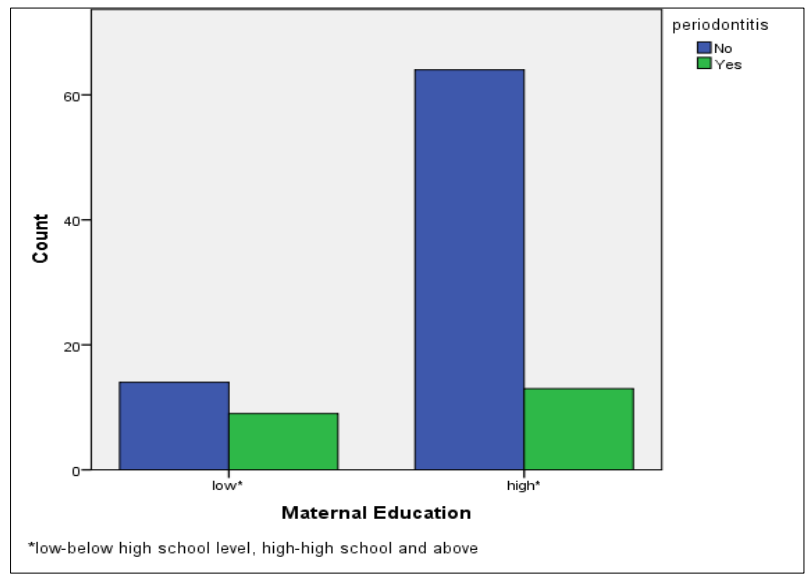

Figure 1: Distribution of subjects with periodontitis according to maternal education.

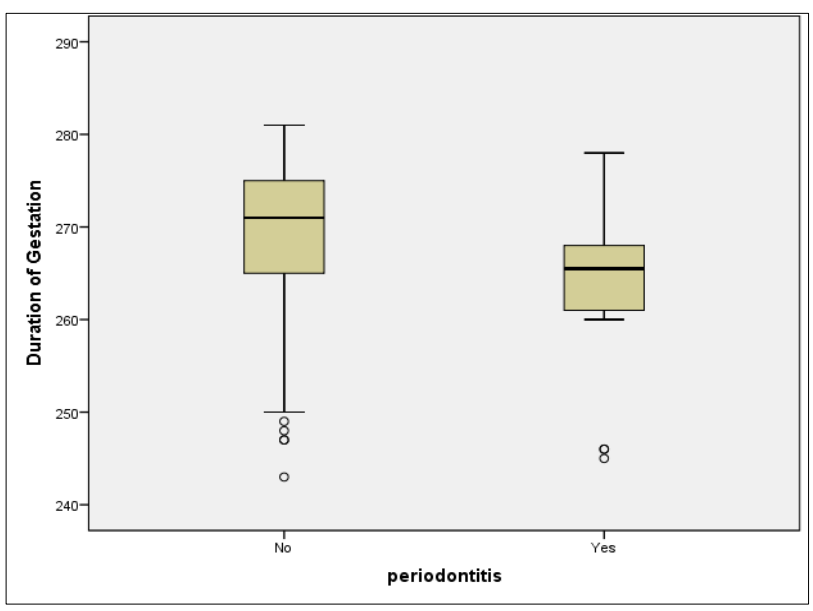

Figure 2: Distribution of 'duration of gestation' in subjects with and without periodontitis.

Table 3: Odds ratio of low birth weight/preterm birth with respect to periodontitis.

\begin{tabular}{|clccl|}
\hline \multirow{3}{*}{ Periodontitis } & $\begin{array}{c}\text { Odds } \\
\text { ratio }\end{array}$ & $\begin{array}{c}\text { 95\% } \\
\text { CI }\end{array}$ & $\begin{array}{l}\text { P } \\
\text { value }\end{array}$ \\
\hline & $\begin{array}{l}\text { Low birth } \\
\text { weight }\end{array}$ & 2.06 & $0.67-6.33$ & 0.2 \\
\cline { 2 - 5 } & $\begin{array}{l}\text { Preterm } \\
\text { birth }\end{array}$ & 0.96 & $0.24-3.8$ & 0.95 \\
\hline
\end{tabular}

The mean birth weight was $2.86 \mathrm{kgs}(\mathrm{SD} \pm 0.4)$, with preterm births averaging $2.3 \mathrm{kgs}(\mathrm{SD} \pm 0.13)$ and term group averaging $2.95 \mathrm{kgs}(\mathrm{SD} \pm 0.35)$. The birth weight in periodontitis group was $2.74 \mathrm{kgs}( \pm 0.36,95 \% \mathrm{CI}=2.57$ -
$2.91)$ and in non-periodontitis group was $2.9 \mathrm{kgs}( \pm 0.41$, 95\% CI=2.81-2.99) $(\mathrm{p}=0.11)$.

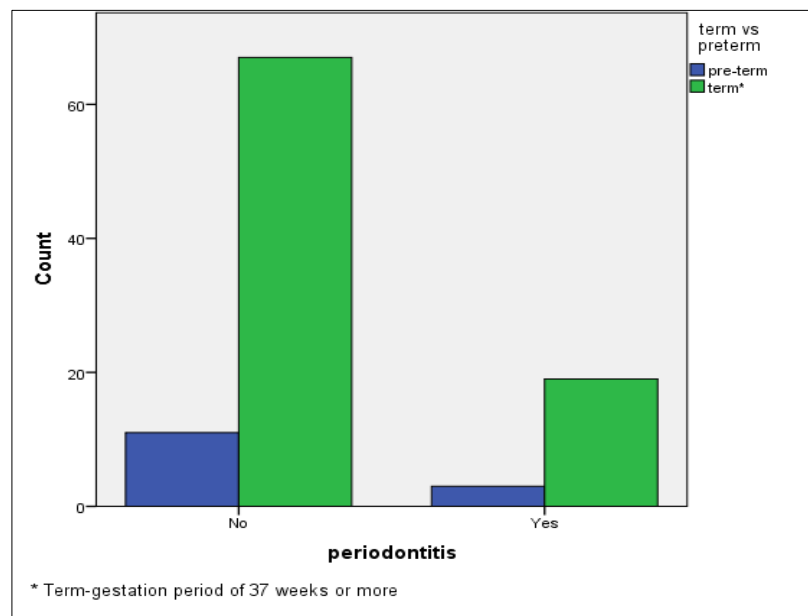

Figure 3: Distribution of term births according to periodontal status.

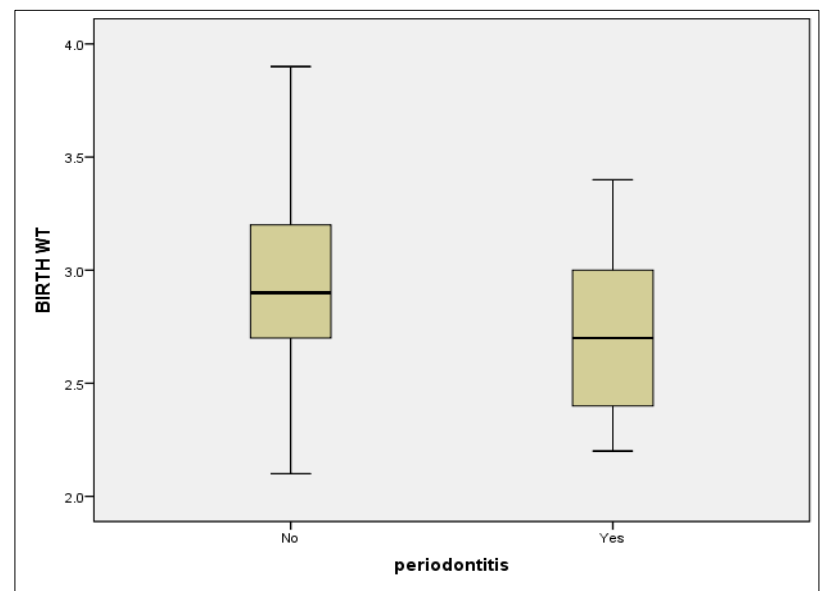

Figure 4: Distribution of birth weight in subjects with and without periodontitis.

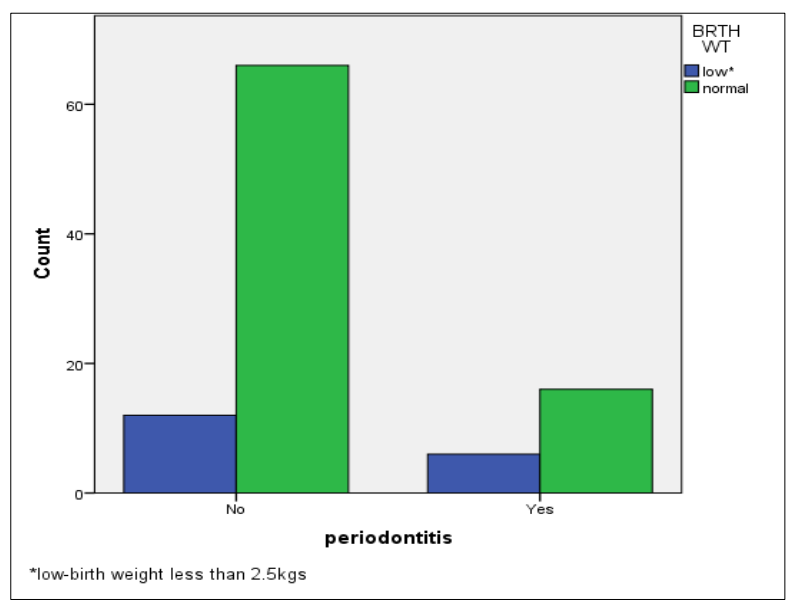

Figure 5: Distribution of low birth weight deliveries according to periodontal status. 
Figure 4 shows the median and quartile distributions of birth weights according to periodontal status. There were 18 deliveries of low birth weight babies, with six occurring in the periodontitis group and 12 in the nonperiodontitis group $(\mathrm{p}=0.22)$. (Figure 5$)$ The odds ratio for low birth delivery in periodontitis group was 2.06 (95\% CI 0.67-6.33, $\mathrm{p}=0.2)$ (Table 3$)$.
There was no significant difference between any complications like anaemia, PIH, chorioamnitis or PPH between the groups. There was no significant correlation between duration of gestation and birth weight with probe depth, clinical attachment level, per-capita income, hemoglobin, blood pressure and blood sugars (Table 4).

Table 4: Correlation between duration of gestation and birth weight with various factors.

\begin{tabular}{|c|c|c|c|c|c|c|c|c|}
\hline \multirow{5}{*}{ Spearmans Rho } & & & Per-capita & RBS & $\mathrm{Hb}$ & BP & $\begin{array}{l}\text { Probe } \\
\text { depth }\end{array}$ & CAL \\
\hline & $\begin{array}{l}\text { Duration of } \\
\text { gestation }\end{array}$ & $\begin{array}{l}\text { Correlation } \\
\text { coefficient }\end{array}$ & -0.010 & 0.097 & -0.146 & 0.002 & -0.162 & -0.181 \\
\hline & & $\begin{array}{l}\text { Significance } \\
\text { ( } 2 \text { tailed })\end{array}$ & 0.918 & 0.338 & 0.147 & 0.982 & 0.106 & 0.072 \\
\hline & $\begin{array}{l}\text { Birth } \\
\text { weight }\end{array}$ & $\begin{array}{l}\text { Correlation } \\
\text { coefficient }\end{array}$ & -0.056 & 0.041 & 0.048 & 0.020 & -0.086 & -0.025 \\
\hline & & $\begin{array}{l}\text { Significance } \\
\text { (2 tailed) }\end{array}$ & 0.580 & 0.685 & 0.638 & 0.840 & 0.397 & 0.806 \\
\hline
\end{tabular}

\section{DISCUSSION}

There are wide discrepancies in health-related indices between urban and rural population, with rural areas having the higher burden on nutrition and infection related problems. However oral health is not received much attention. In this study we attempted to determine the prevalence of periodontitis in the pregnant woman population. Our cohort is unique in that it was from rural areas, a traditionally underserved population. In our study, the prevalence of periodontitis was $22 \%$. The reported prevalence of periodontal disorders ranges from 10 to $78 \%$ in literature. Periodontal disorders can affect $42 \%$ of general population in rural India and 31 to $50 \%$ among pregnant population. ${ }^{12}$ The wide variations in the reported prevalence of periodontitis are mainly due to the different diagnostic criteria employed in the studies. Studies have reported that prevalence of periodontitis increases with age which could be due to changes in host immunity and the cumulative effect of the untreated disease process over the time. ${ }^{13}$ A relatively younger population in our study may also contribute to the lower observed prevalence of periodontitis. Findings similar to our study was reported by Piscoya et al from South America. ${ }^{14}$ The lower prevalence of periodontitis in this study could be due to better awareness about hygiene. Maternal formal education levels and maternal employment were the only factors that were found to be significantly associated with the development of periodontitis. Pregnant woman with relatively higher levels of formal education (beyond primary schooling) had a lower prevalence of periodontitis. Though maternal employment status was also found to be associated with periodontitis, the finding could be secondary to better schooling and not income. In fact there was no difference in the prevalence of periodontitis between the different socio-economic strata. Education creates awareness and can influence the attitude and practice of people towards healthy lifestyles, nutrition and preventive aspects of health care. This is reflected by the universal adaptation of daily brushing of teeth using a tooth brush by all the subjects and higher average number of ante-natal contacts compared to the recommended minimal of 3 ANCs by government of India (but still less than 8 ANCs recommended by WHO) and lower prevalence of anaemia $(64 \%)$ compared to greater than $73 \%$ reported. ${ }^{15-}$

17 An inverse relation between maternal education and periodontitis was reported from Nigerian women in university campus area. ${ }^{18}$ However a study from Chandigarh found no significant association between maternal education level and periodontitis but women from higher socio-economic strata were less likely to have periodontitis. ${ }^{19}$ It would be interesting to know if the maternal education would show similar influence outside of the areas adopted by our institution.

We also found no association between the types of housing, source of drinking water. Uncontrolled hypothyroidism is associated with destruction of periodontum due to higher salivary TNF $\alpha$ and IL6 levels. ${ }^{20}$ Since pregnant women are routinely screened for hypothyroidism and treated if necessary, its effect may not have been evident in our study.

The mean probe depth was $2.87 \mathrm{~mm}$ and $4.27 \mathrm{~mm}$ in group without and with periodontitis. $\mathrm{S}$ Moore et al reported a much lower mean probe depths of $1.59 \mathrm{~mm}$ and $2.78 \mathrm{~mm}$ in pregnant women without and with periodontitis. ${ }^{21}$ 
The pre-term birth rate was $14 \%$ in the group which is comparable to the national average of $12.9 \%$ reported in the national health portal of India. ${ }^{22}$ However this is still higher than the $7 \%$ reported in United Kingdom. Low birth weight rate was $18 \%$ in our study. Sudha G et al reported that $34 \%$ of babies born in Chittoor district of Andhra Pradesh to be of low birth weight. ${ }^{23}$ In the present study, $34 \%$ of subjects were less than 20 years age, $44 \%$ between 21-25 year age, and 20\% between 26-30 year ages. This distribution is similar that reported in study by Sudha $G$ et al. $77 \%$ of subjects in our cohort had received education of high school or higher compared to $6.5 \%$ in study by Sudha G et al. ${ }^{23}$ Pre-term births and low birth weight are associated with significant peri-natal morbidity and mortality. Many of the traditional risk factors for periodontitis overlap with that of pre-term births and low birth weight.

The mean probe depth was $3.29 \pm 0.63 \mathrm{~mm}$ and $3.21 \pm 0.43 \mathrm{~mm}(\mathrm{p}=0.8)$ in the term and pre-term group. There appeared to be no relationship between periodontitis and pre-term births in our group. However the average gestational age was higher in the group without periodontitis. Probe depth was $3.15 \pm 0.6 \mathrm{~mm}$ and $3.33 \pm 0.61 \mathrm{~mm}$ in normal and low birth weight group. There appears to be no association between periodontitis and low birth weight of babies. Govindaraju $\mathrm{P}$ et al reported significant difference in $\mathrm{PD}$ between term and pre-term births $(2.86 \pm 0.54$ vs $5.83 \pm 0.86, \mathrm{p}=0.001) .{ }^{24} \mathrm{~A}$ study from Kosovo reported PD of $2.26 \pm 0.49 \mathrm{~mm}$ and $2.49 \pm 0.49 \mathrm{~mm}$ in term and pre-term deliveries. The PD was $2.27 \pm 0.50 \mathrm{~mm}$ and $2.46 \pm 0.47 \mathrm{~mm}$ in woman with normal and low birth weight babies $(\mathrm{p}=0.03)$. The birth weight was $3.2 \pm 0.68 \mathrm{kgs}$ and $2.75 \pm 1 \mathrm{kgs}(\mathrm{p}=0.0003)$ and the gestation period $38.6 \pm 2.7$ weeks and $36.4 \pm 4.8$ weeks $(\mathrm{p}=0.0001)$ in the normal and periodontitis groups in their cohort. $^{25}$

Limitations of our study are: This study has a power of $62 \%$ and is not adequately powered. We did not have significant numbers of higher-grade periodontitis. Selection bias cannot be ruled out due to convenience sampling method adopted. We used partial mouth recording of periodontal variables to minimize patient discomfort which can under diagnose periodontitis.

\section{CONCLUSION}

There appears to be no association between mild to moderate maternal periodontal disease and preterm birth or low birth weight birth in our cohort. Effect of severe periodontal disease on pregnancy outcomes need further evaluation.

\section{Funding: No funding sources}

Conflict of interest: None declared

Ethical approval: The study was conducted in accordance with the ethical standards of the institutional and/or national research committee and with the 1964
Helsinki declaration and its later amendments or comparable ethical standards

\section{REFERENCES}

1. Hess RF, Gilill CS, DembÃ J. Prevalence and Predictors of Periodontal Disease among Pregnant Women in Mali, West Africa. Annals of Medical and Health Sciences Research. 2017;7(4). Available at: https://www.amhsr.org/abstract/prevalence-andpredictors-of-periodontal-disease-among-pregnantwomen-in-mali-west-africa-3595.html. Accessed 2 May 2019.

2. Ha JE, Jun JK, Ko HJ, Paik DI, Bae KH. Association between periodontitis and preeclampsia in neversmokers: a prospective study. J Clinic Periodontol. 2014;41(9):869-74.

3. Abariga SA, Whitcomb BW. Periodontitis and gestational diabetes mellitus: a systematic review and meta-analysis of observational studies. BMC pregnancy and childbirth. 2016;16(1):344.

4. Ananth CV, Andrews HF, Papapanou PN, Ward AM, Bruzelius E, Conicella ML, et al. History of periodontal treatment and risk for intrauterine growth restriction (IUGR). BMC oral health. 2018;18(1):161.

5. Zi MY, Longo PL, Bueno-Silva B, Mayer MP. Mechanisms involved in the association between periodontitis and complications in pregnancy. Frontiers in pub health. 2015;2:290.

6. Jacob PS, Nath S. Periodontitis among poor rural Indian mothers increases the risk of low birth weight babies: a hospital-based case control study. J Periodont Implant Sci. 2014;44(2):85-93.

7. Tellapragada C, Eshwara VK, Bhat P, Acharya S, Kamath A, Bhat S, Rao C, Nayak S, Mukhopadhyay C. Risk factors for preterm birth and low birth weight among pregnant Indian women: a hospital-based prospective study. J Prevent Med Pub Health. 2016;49(3):165.

8. Muwazi L, Rwenyonyi CM, Nkamba M, Kutesa A, Kagawa M, Mugyenyi G, et al. Periodontal conditions, low birth weight and preterm birth among postpartum mothers in two tertiary health facilities in Uganda. BMC oral health. 2014;14(1):42.

9. Santa Cruz I, Herrera D, Martin C, Herrero A, Sanz M. Association between periodontal status and preterm and/or low-birth weight in S pain: clinical and microbiological parameters. J Periodont Res. 2013;48(4):443-51.

10. Iheozor-Ejiofor Z, Middleton P, Esposito M, Glenny AM. Treating periodontal disease for preventing adverse birth outcomes in pregnant women. Cochrane Database of Systematic Reviews. 2017(6).

11. Gomes-Filho IS, Trindade SC, Passos-Soares JS. Clinical diagnosis criteria for periodontal disease: an update. J Dent Health Oral Disord Ther. 2018;9(5):354-6.

12. Balaji SK, Lavu V, Rao S. Chronic periodontitis prevalence and the inflammatory burden in a sample 
population from South India. Ind J Dental Res. 2018;29(2):254.

13. Wu YM, Liu J, Sun WL, Chen LL, Chai LG, Xiao X, Cao Z. Periodontal status and associated risk factors among childbearing age women in Cixi City of China. J Zhejiang Uni Sci B. 2013;14(3):231-9.

14. Piscoya MD, Ximenes RA, Silva GM, Jamelli SR, Coutinho SB. Periodontitis-associated risk factors in pregnant women. Clinics. 2012;67(1):27-33.

15. Prashant D, Jaideep KC, Girija A, Mallapur MD. Prevalence of anemia among pregnant women attending antenatal clinics in rural field practice area of Jawaharlal Nehru Medical College, Belagavi, Karnataka, India. International J Comm Med Pub Heal. 2017;4(2):537-41.

16. Antenatal care in India: what's missing? Available at:

https://blogs.lshtm.ac.uk/hppdebated/2013/10/29/ant enatal-care-in-india-whats-missing/. Accessed 2 May 2019.

17. WHO | New guidelines on antenatal care for a positive pregnancy experience. WHO. Available at: http://www.who.int/reproductivehealth/news/antenat al-care/en/. Accessed 2 May 2019.

18. Onigbinde OO, Sorunke ME, Braimoh MO, Adeniyi AO. Periodontal status and some variables among pregnant women in a Nigeria tertiary institution. Annals Med Health Sci Res. 2014;4(6):852-7.

19. Dhaliwal JS, Lehl G, Sodhi SK, Sachdeva S. Evaluation of socio-demographic variables affecting the periodontal health of pregnant women in Chandigarh, India. J Ind Soc Periodontol. 2013;17(1):52.

20. Monea A, Elod N, Sitaru A, Stoica A, Monea M. Can Thyroid Dysfunction Induce Periodontal
Disease?. European Scientific J. 2014 May 1;10(15). Available at: https://eujournal.org/index.php/esj/article/view/3440.

21. Moore S, Ide M, Coward PY, Randhawa M, Borkowska E, Baylis R, Wilson RF. A prospective study to investigate the relationship between periodontal disease and adverse pregnancy outcome. British Dental J. 2004;197(5):251.

22. Preterm birth | National Health Portal of India. Available at: https://www.nhp.gov.in/disease/reproductivesystem/female-gynaecological-diseases-/pretermbirth. Accessed 18 April 2019.

23. Sudha G, T, Reddy lam M, Narasimhulu S, Kod K, Reddy A, et al. Prevalence and Correlates of Low Birth Weight in Chittoor District of Andhra Pradesh, India. Obstet Gynecol Int J. 2017;7(1):1-0.

24. Govindaraju P, Venugopal S, Shivakumar MA, Sethuraman S, Ramaiah SK, Mukundan S. Maternal periodontal disease and preterm birth: A case-control study. J Ind Soc Periodontol. 2015;19(5):512.

25. Meqa K, Dragidella F, Disha M, Sllamniku-Dalipi Z. The association between periodontal disease and preterm low birthweight in Kosovo. Acta Stomatol Croatica. 2017;51(1):33-40.

Cite this article as: Munivenkatappa $S$, Govindaraj SM. Maternal periodontitis and its influence on duration of gestation and fetal birth weight. Int $\mathbf{J}$ Reprod Contracept Obstet Gynecol 2019;8:3194-200. 